Mater. Res. Soc. Symp. Proc. Vol. 1193 @ 2009 Materials Research Society

\title{
Understanding Radionuclide Migration from the D1225 Shaft, Dounreay, Caithness, UK
}

David Savage $^{1}$, Claire Watson ${ }^{1}$, James Wilson ${ }^{1}$, Alex Bond ${ }^{1}$, Warren Jones ${ }^{2}$, Richard Metcalfe ${ }^{1}$, Tony Milodowski ${ }^{3}$, Colin Munro ${ }^{2}$, James Penfold ${ }^{1}$ and Sarah Watson ${ }^{1}$

${ }^{1}$ Quintessa Limited, The Hub, 14 Station Road, Henley-on-Thames, RG9 1AY, UK

${ }^{2}$ Dounreay Site Restoration Limited, Dounreay, Thurso, Caithness, KW14 7TZ, UK

${ }^{3}$ British Geological Survey, Keyworth, Nottinghamshire, NG12 5GG, UK

\begin{abstract}
A $65 \mathrm{~m}$ vertical shaft was sunk at Dounreay in the 1950s to build a tunnel for the offshore discharge of radioactive effluent from the various nuclear facilities then under construction. In 1959, the Shaft was licensed as a disposal facility for radioactive wastes and was routinely used for the disposal of ILW until 1970. Despite the operation of a hydraulic containment scheme, some radioactivity is known to have leaked into the surrounding rocks. Detailed logging, together with mineralogical and radiochemical analysis of drillcore has revealed four distinct bedding-parallel zones of contamination. The data show that $\mathrm{Sr}-90$ dominates the bulk beta/gamma contamination signal, whereas $\mathrm{Cs}-137$ and $\mathrm{Pu}-248 / 249$ are found only to be weakly mobile, leading to very low activities and distinct clustering around the Shaft. The data also suggest that all uranium seen in the geosphere is natural in origin. At the smaller scale, contamination adjacent to fracture surfaces is present within a zone of enhanced porosity created by the dissolution of carbonate cements from the Caithness flagstones during long-term rockwater interactions. Quantitative modelling of radionuclide migration, using the multiphysics computer code QPAC shows the importance of different sorption mechanisms and different mineralogical substrates in the Caithnesss flagstones in controlling radionuclide migration.
\end{abstract}

\section{INTRODUCTION}

A $65 \mathrm{~m}$ vertical shaft was sunk at Dounreay in the 1950s to build a tunnel for the offshore discharge of radioactive effluent ('LEDT') from the various nuclear facilities then under construction. In 1959, the Shaft was licensed as a disposal facility for radioactive wastes and was routinely used for the disposal of ILW until 1970. All consignments to the Shaft ceased in 1977 following an explosion in the head-space above the waste column. In 1998, it was decided to retrieve the waste for treatment and surface storage. The first phase of decommissioning is hydraulic isolation, creating a containment barrier between the waste and the groundwater that flows through the surrounding rock. This has involved grouting 400 boreholes in a $10 \mathrm{~m}$ wide band of rock around the Shaft. Despite the operation of a hydraulic containment scheme, some radioactivity is known to have leaked into the surrounding rocks.

The Shaft is unlined so that wastes are currently in direct contact with shallow-dipping micaceous siltstones and sandstones (flagstones) of the Middle Devonian Dounreay Shore Formation. Logging of the macroscopic mineralogical features, and detailed mineralogical analysis of the drillcore from boreholes, has indicated the importance of natural rock 'weathering' reactions that have produced Fe and Mn oxyhydroxides and a variety of clay 
minerals along principal zones of groundwater flow, as well as increasing the porosity of such alteration zones. The work presented here is a quantitative assessment of radionuclide migration, taking into account 'chemical' retardation mechanisms. This is an attempt to model radionuclide retardation realistically from a chemical perspective and serves as a counterpoint to necessary simplifying assumptions regarding these processes incorporated into current assessment models.

\section{DISTRIBUTION OF CONTAMINATION}

Data for radioactive contamination in the geosphere around the Shaft have recently been compiled and have demonstrated that contamination is dominantly associated with zones of higher bulk permeability and on individual (mainly bedding-parallel) discontinuities with enhanced porosity due to long-term rock-groundwater interactions, and that there are four readily identifiable zones of contamination. The bulk $\beta / \gamma$ contamination is dominated by Sr-90, whereas other radionuclides have limited mobility and are close to the limit of detection near the Shaft. Any uranium detected in the geosphere appears to be natural in origin. Some contamination has moved a horizontal distance of $85 \mathrm{~m}$ from the Shaft following the stratigraphic layering. Radioactivity is mostly associated with clays in the rock matrix, but also on iron oxyhydroxides due to oxidative weathering of siderite and pyrite, on micas on fracture surfaces, and in barite $\left(\mathrm{BaSO}_{4}\right)$ formed on discontinuity surfaces due to groundwater mixing.

Mineralogical and geochemical studies have shown that sorption occurs via reversible ion exchange on clays ( $\mathrm{Sr}$ ), irreversible ion exchange on mica (Cs), by surface complexation on iron oxyhydroxides (actinides, $\mathrm{Sr}$ ), and by incorporation into barite ( $\mathrm{Sr}$ ). Radionuclide migration from the Shaft is also affected by variations in groundwater chemistry, in that there are two distinct groundwater systems - oxidising, brackish groundwater above $\sim 30 \mathrm{~m}$ depth (iron staining and porosity enhancement along groundwater flowpaths), and chemically-reducing fresh water below. Strong biannual variations in the salinity of groundwaters, ascribed to winter peaks in salinity due to increased storm activity and application of salt to roads may contribute to the migration of radionuclides by inducing desorption of cations. Although chemical conditions in groundwater around the Shaft are broadly oxidising, local chemical conditions within the Shaft are assumed to be reducing, due to the absence of mobile oxidised forms of variable valence radionuclides as contamination in the geosphere. This is most likely due to the degradation of organics and the corrosion of metals disposed within the Shaft.

\section{MODEL INPUT}

A conceptual model illustrating the interaction between water flow, diffusion, and sorption describing the migration of radionuclides along a discontinuity is shown in Figure 1. Advection of groundwater is assumed to take place only in the discontinuity itself, with diffusion of contaminants enabled in a zone of alteration around a discontinuity. The rock matrix is a zone of reduced porosity, hydraulic conductivity, and diffusion. It is assumed that mica on discontinuity surfaces is responsible for sorption of $\mathrm{Cs}$, whereas $\mathrm{Sr}, \mathrm{U}$, and $\mathrm{Pu}$ are retarded both by diffusion into the rock matrix and by sorption on clay $(\mathrm{Sr})$ and $\mathrm{Fe}$ oxyhydroxides $(\mathrm{U}, \mathrm{Pu})$. 


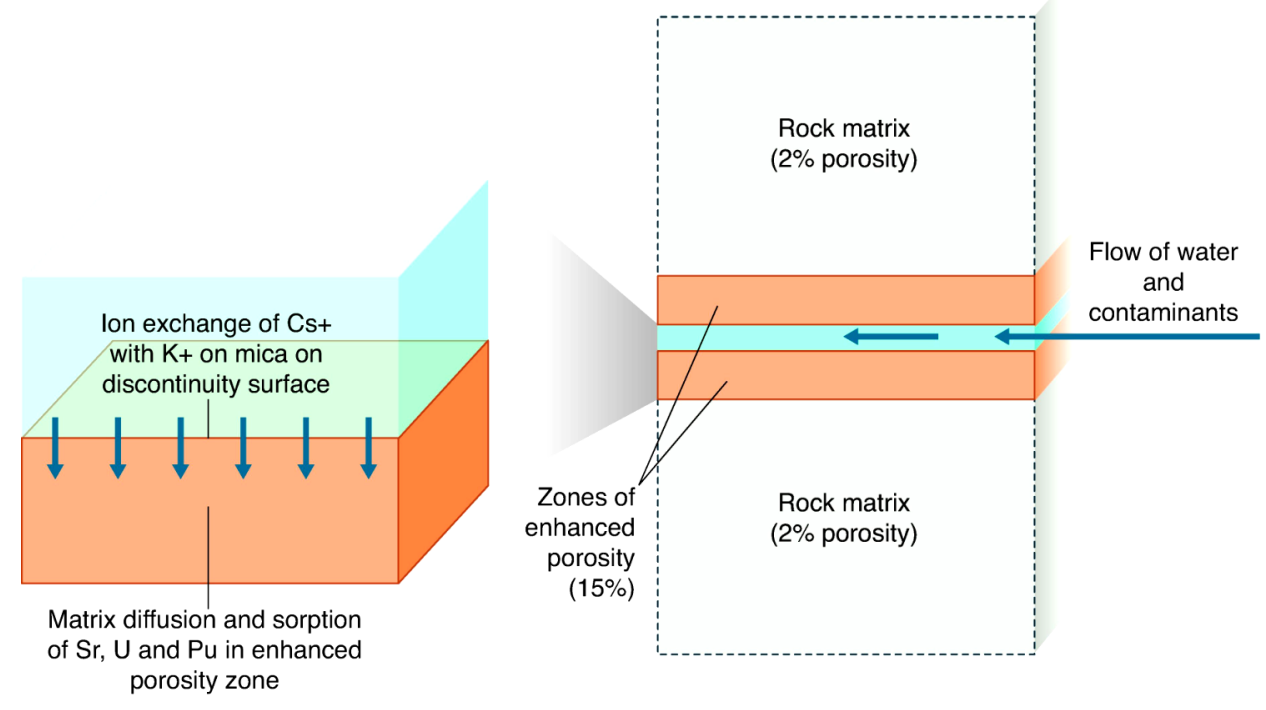

Figure 1. Conceptual model of water flow, diffusion, and sorption along discontinuities in the Dounreay Shore formation around the Shaft.

The effective thickness of typical bedding plane discontinuities Dounreay is in the order of 20-250 $\mu \mathrm{m}$. A typical mean hydraulic conductivity for a $2 \mathrm{~m}$ thick section of the local Dounreay Shore formation is $5 \mathrm{E}-7 \mathrm{~m} \mathrm{~s}^{-1}$, with a head gradient of 0.015 . Typically, a $2 \mathrm{~m}$ section contains two discontinuity surfaces, so that if the conductivity of the matrix is approximately $1 \mathrm{E}-10 \mathrm{~m} \mathrm{~s}^{-1}$, then for the Base Case model values of $1.1 \mathrm{E}-3 \mathrm{~m} \mathrm{~s}^{-1}$ for the discontinuity and $1.1 \mathrm{E}-5 \mathrm{~m} \mathrm{~s}^{-1}$ for the alteration zone were adopted (assuming that the discontinuity has a conductivity two orders of magnitude greater than that for the alteration zone). In model variants where the thicknesses of the alteration region and discontinuity were altered, the hydraulic conductivities were adjusted accordingly. Measurement of transport properties (diffusion coefficients, porosity) of samples of Dounreay Shore Formation show that porosities adjacent to the discontinuity surfaces for samples with a significant alteration zone ranged from 11 to $18 \%$ [1]. Here, porosity values of 15 and $2 \%$ and diffusion coefficients of $3 \mathrm{E}-11$ to $3 \mathrm{E}-12 \mathrm{~m}^{2} \mathrm{~s}^{-1}$ were adopted for the alteration zone and the matrix, respectively.

The behaviour of $\mathrm{Sr}$ is characterised by reversible ion exchange which is similar to the behaviour of Sr-90 in radioactively contaminated sediments elsewhere [2]. The exchanger phase in the Dounreay Shore Formation is most probably corrensite (mixed-layer smectite-chlorite) present in the bulk rock matrix. In the absence of Dounreay-specific data, ion exchange constants with respect to $\mathrm{Na}^{+}$for a generic (smectite) clay 'ion exchanger' were employed [3].

Cs behaviour is characterised by irreversible ion exchange on mica, principally on bedding-parallel discontinuity surfaces. Although there are no Dounreay site-specific sorption data for Cs, a model for Cs uptake by ion exchange which is generally applicable to illite-bearing rocks has been adopted [4]. In this model, Cs sorption is dominated by mica and there is a fixed relationship between the capacities of main sorption sites ('frayed edge', 'type II', and 'planar'). 
For $\mathrm{U}$ and $\mathrm{Pu}$, the simplest of surface complexation models, the 'non-electrostatic model' (NEM) described by [5] has been employed, with all sorption of $\mathrm{U}$ and $\mathrm{Pu}$ in the geosphere around the Shaft assumed to occur on iron oxyhydroxides. Moreover, migration of uranium is assumed to occur as the uranyl $(6+)$ ion, despite evidence that $U$ may be fixed as the less-mobile $\mathrm{U}^{4+}$ in the reduced chemical conditions of the Shaft. The model described assumes a surface area of $50 \mathrm{~m}^{2} \mathrm{~g}^{-1}$ for goethite and a site capacity of 2.31 sites $/ \mathrm{nm}^{2}$ or $0.205 \mathrm{~mol}$ sites $/ \mathrm{mol}$.

Source-term concentrations of 1E-9, 1E-10, 4E-10, and 2E-7 mol $1^{-1}$ were used for Sr, Cs, $\mathrm{U}$ and $\mathrm{Pu}$ respectively. A model variant investigated the effects of decreasing the Pu source-term by two orders of magnitude.

The modelled system consisted of groundwater flow along a planar discontinuity, $100 \mathrm{~m}$ long x $1 \mathrm{~m}$ wide, with matrix diffusion occurring normal to this feature in a zone of enhanced porosity. The model had increased discretisation at the inlet, with $10 \times 0.1 \mathrm{~m}$ compartments, followed by $9 \times 1 \mathrm{~m}$, and the remainder consisting of $10 \mathrm{~m}$ sections. Model cases (Table I) examined variations in: alteration zone thickness; water chemistry; amounts of sorptive minerals; and discontinuity aperture. A variant with a $K_{d}$ for $\operatorname{Sr}\left(0.01 \mathrm{~m}^{3} \mathrm{~kg}^{-1}\right)$ was also investigated for comparison with ion exchange cases.

The conceptual model described above was modelled using Quintessa's general-purpose modelling code, QPAC. QPAC contains a fully coupled reactive-transport module, including mineral precipitation and dissolution, ion exchange and surface complexation. Discretisation in this module is based on the control volume approach, with the system split into a number of volumes or 'compartments', which are linked to each other via interfaces.

Table I. Calculational cases considered in the modelling.

\begin{tabular}{|c|c|c|c|c|}
\hline Case & $\begin{array}{l}\text { Fracture } \\
\text { aperture } \\
(\mu \mathrm{m})\end{array}$ & Groundwater & $\begin{array}{c}\text { Alteration zone } \\
\text { thickness } \\
(\mathbf{m})\end{array}$ & $\begin{array}{l}\text { Sorbent } \\
\text { vol \% }\end{array}$ \\
\hline 1 Base case & 250 & brackish & 0.01 & Mica $-50 ;$ clay $-21.25 ;$ Fe-oxide -8.5 \\
\hline 2 Thin AZ & " & "“ & 0.005 & 然 \\
\hline $\begin{array}{l}3 \text { Changing water } \\
\text { composition }\end{array}$ & “ & $\begin{array}{l}\text { Pulsed with } \\
\text { fresh water }\end{array}$ & 0.01 & “" \\
\hline 4 Fewer minerals & “" & brackish & "، & Mica -5 ; clay $-2.125 ;$ Fe-oxide -0.85 \\
\hline 5 Small aperture & 170 & " & “" & Mica $-50 ;$ clay $-21.25 ;$ Fe-oxide -8.5 \\
\hline
\end{tabular}

\section{RESULTS AND DISCUSSION}

A comparison of the output of the modelling and field data for $\mathrm{Sr}$ is shown in Figure 2. Since the field data are a compilation of data from the four different zones of contamination around the Shaft, each with slightly different groundwater flow rates, discontinuity apertures, mineralogical compositions, and physical properties (porosity and permeability), these data have been represented as a geometric mean to reduce the inevitable scatter and variability due to the sampling across different discontinuity zones.

The modelled peak value of $\mathrm{Sr}$ in the Base Case is $1 \mathrm{E} 8 \mathrm{~Bq} / \mathrm{kg}$ at the Shaft wall, decreasing to $1 \mathrm{E} 2 \mathrm{~Bq} / \mathrm{kg} 50 \mathrm{~m}$ down-gradient of the Shaft. Measured Sr ranges up to about $1.0 \mathrm{E} 6 \mathrm{~Bq} / \mathrm{kg}$, but is mostly between $1 \mathrm{E} 3$ and $1 \mathrm{E} 5 \mathrm{~Bq} / \mathrm{kg}$, and may extend $50-70 \mathrm{~m}$ from the Shaft (Figure 2). 


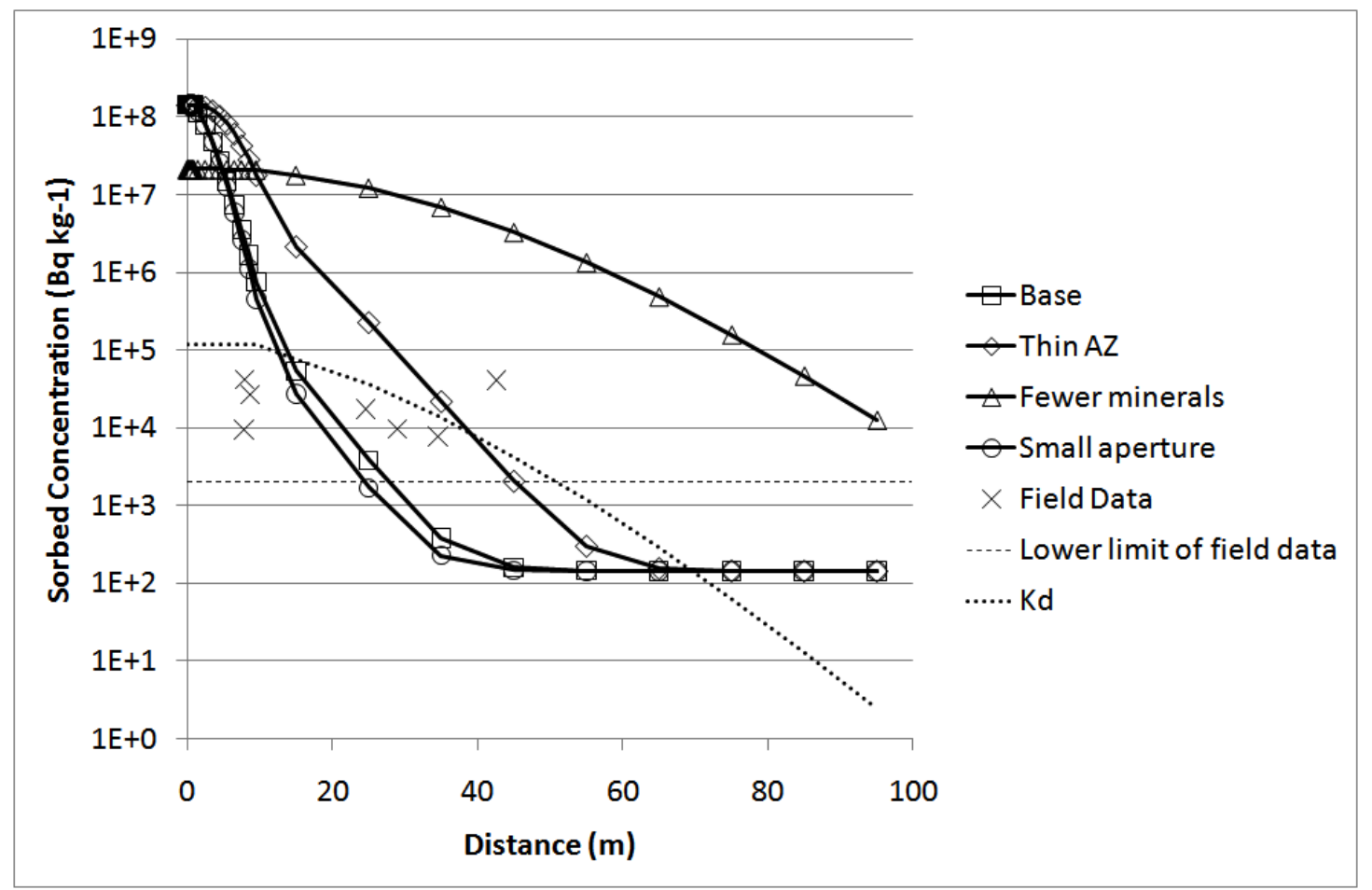

Figure 2. Comparison between modelled results (Base Case, thinner alteration zone, fewer sorptive minerals, smaller aperture and $K_{d}$ variants) and the geometric mean of the field data for sorbed Sr. The dashed horizontal line indicates the lowest detectable limit for the field data.

The modelled Sr front is at about 40-60 $\mathrm{m}$ in the Base Case and at about $100 \mathrm{~m}$ in the variant with a factor of ten fewer sorbing minerals. The model using a $K_{d}$ representation of sorption passes through the geometric mean of the measured data and offers the closest comparison with the field data. The chemically-based models all suggest higher levels of $\mathrm{Sr}$ nearer the Shaft than the $K_{d}$-based model. A variant examining the effect of the annual variation in salinity in the groundwater on Sr mobility was investigated by cycling the boundary condition at the Shaft side of the model with a brackish groundwater composition for half the year and fresh water for the other half (Case 3 in Table I). However, the concentration of Sr on the boundary was maintained throughout the simulation. The expectation was that $\mathrm{Sr}$ would sorb onto clay surfaces during the fresh water cycles but be replaced by Na during the brackish water cycles. This was indeed found to be the case; Figure 3 shows how the concentration of aqueous $\mathrm{Sr}$ varies with time in the first alteration region compartment (nearest the Shaft). Brackish water is introduced first, followed by fresh water after 0.5 years. Although the concentration of $\mathrm{Sr}$ in both these waters is the same, in the alteration region the aqueous concentration increases whenever brackish water is introduced to the system since the salinity acts to dislodge sorbed $\mathrm{Sr}$ from the clay. In comparison to the base case, where brackish water is used as a constant boundary condition, this more realistic case with varying salinity leads to reduced mobility of Sr. As expected, if the results are compared to a case where fresh water is used as a constant boundary condition, the mobility of Sr is increased. 


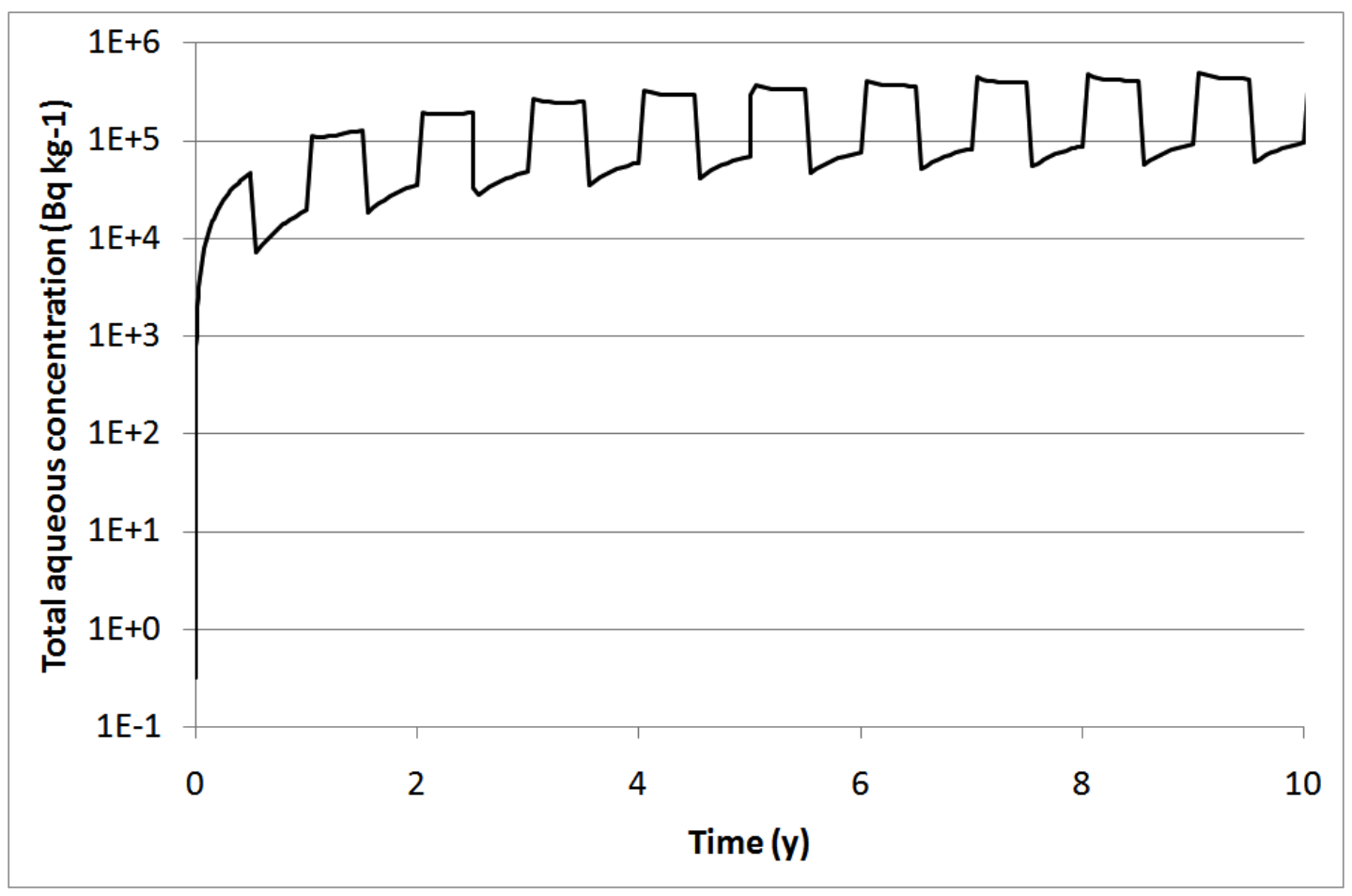

Figure 3. Evolution of the total aqueous concentration of $\mathrm{Sr}$ in the first alteration region compartment. Only the first 10 years are shown in order to resolve the cyclical behaviour.

Measured sorbed Cs ranges up to about $1.0 \mathrm{E} 5 \mathrm{~Bq} / \mathrm{kg}$, but away from the Shaft is generally about $1.0 \mathrm{E} 1 \mathrm{~Bq} / \mathrm{kg}$ where detected (Figure 4). Measured data are therefore about an order of magnitude greater than those modelled in the Base Case (a peak of 1.0E4 Bq/kg, decreasing to a background of about $1.0 \mathrm{E}-1 \mathrm{~Bq} / \mathrm{kg}$ ). The Cs front is at about $5-7 \mathrm{~m}$ from the Shaft in the modelled Base Case and at about $10 \mathrm{~m}$ from the Shaft for the measured data.

The model variant with a factor of ten fewer minerals broadens the Cs sorption front somewhat and produces much lower activities of Cs in distal regions ( $>25 \mathrm{~m}$ away) from the Shaft (about $1 \mathrm{E}-2 \mathrm{~Bq} / \mathrm{kg}$ ) than those measured. The modelled data thus underestimate by an order of magnitude the measured Cs activities around the Shaft.

The sparse measured sorbed $\mathrm{Pu}$ values range up to $2.0 \mathrm{e} 2 \mathrm{~Bq} / \mathrm{kg}$, but are generally about 1 $\mathrm{Bq} / \mathrm{kg}$ where detected. In the Base Case, modelled data decrease from about 1.0e8 at the Shaft wall to a 'background of $5.0 \mathrm{e} 2 \mathrm{~Bq} / \mathrm{kg}$ about $7 \mathrm{~m}$ from the Shaft. With a more realistic source term in the Shaft of $2.0 \mathrm{E}-9 \mathrm{~Bq} / \mathrm{kg}$ for Pu, then modelled data peak at $1.0 \mathrm{e} 6 \mathrm{~Bq} / \mathrm{kg}$ at the Shaft wall, decreasing to a background value of $4.0 \mathrm{E} 2 \mathrm{~Bq} / \mathrm{kg}$ at $3 \mathrm{~m}$ from the Shaft.

Measured sorbed $\mathrm{U}$ range up to $1.0 \mathrm{E} 2 \mathrm{~Bq} / \mathrm{kg}$ in some instances, but are generally about $5.0 \mathrm{E} 1 \mathrm{~Bq} / \mathrm{kg}$. Modelled data decrease from $1 \mathrm{~Bq} / \mathrm{kg}$ at the Shaft wall to a level of $3.0 \mathrm{E}-4 \mathrm{~Bq} / \mathrm{kg}$ at about 4-5 $\mathrm{m}$ down-gradient in the Base Case. Modelled data are thus five orders of magnitude less than those measured. Even with a pessimistic assumption of the occurrence of uranium as the oxidised uranyl $\left(\mathrm{U}^{\mathrm{VI}}\right)$ ion, the modelled data confirm that the anthropogenic $\mathrm{U}$ contribution to rock contamination is likely to be very small. The content of natural uranium in the Dounreay Shore Formation is in the order of $1 \mathrm{mg} \mathrm{kg}^{-1}$. 


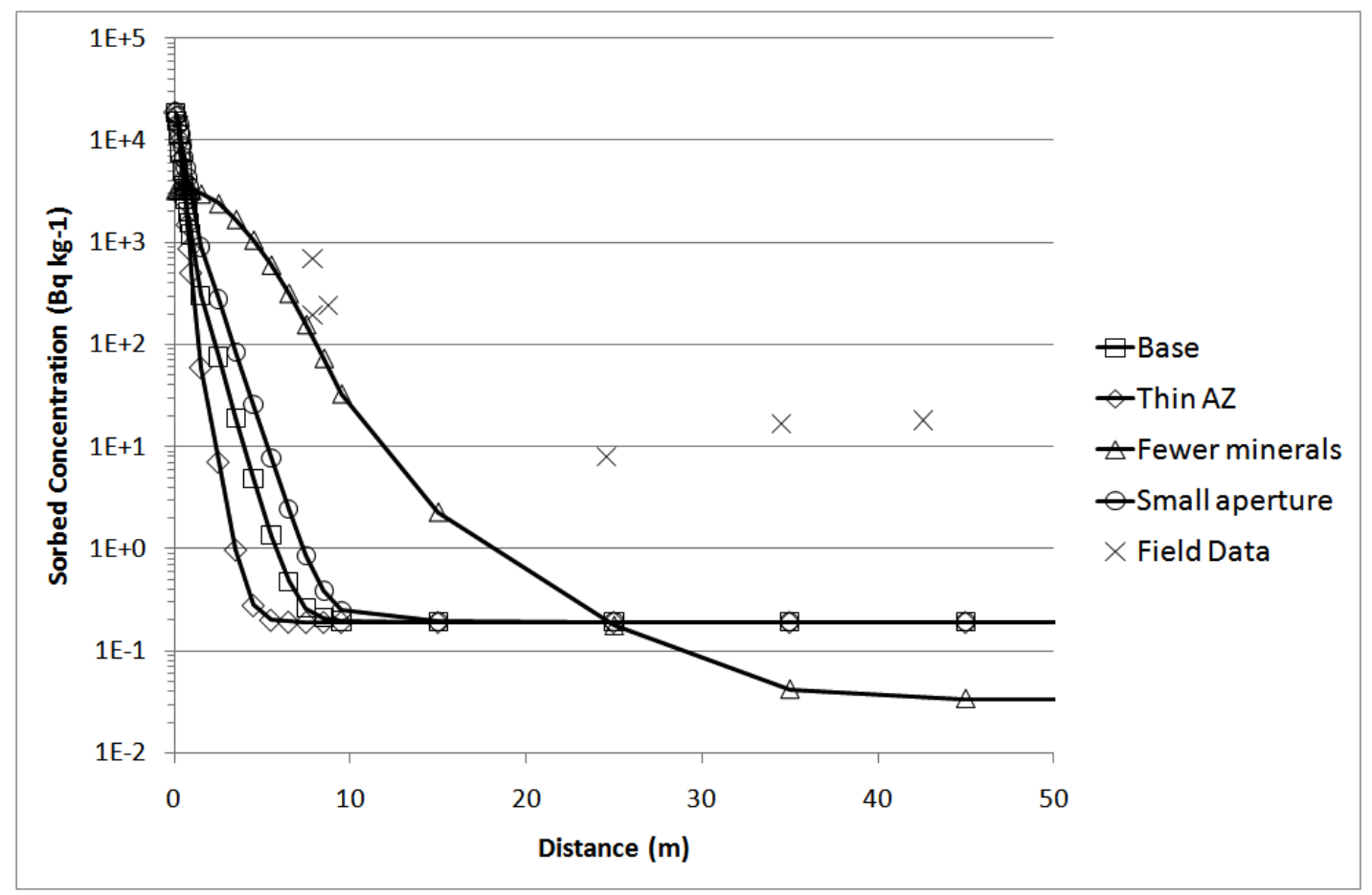

Figure 4. Comparison between modelled results and field data for sorbed Cs.

For the fewer sorbing minerals variant (Case 4 in Table I), the amounts of the sorbing minerals were reduced by an order of magnitude. It was expected that this would allow the radionuclides to travel further away from the Shaft, and this was found to be the case with Cs and Sr. Elevated levels of Sr were predicted at the far edge of the model domain, $100 \mathrm{~m}$ from the shaft. However the story for $\mathrm{U}$ and $\mathrm{Pu}$ was different; these radionuclides were barely affected by the reduction in surface sites which is a reflection of the spare capacity of available surface sites on the Fe-oxyhydroxide.

In another variant, the size of the discontinuity was reduced from 200 to $170 \mu \mathrm{m}$ (Case 2 in Table I). Although the results did not differ greatly from the Base Case, it was observed that the total aqueous concentration of Cs was increased. This is due to the fact that Cs sorbs onto mica in the discontinuity, whilst the other species sorb onto minerals in the alteration region.

\section{CONCLUSIONS}

The results of the modelling have shown that the following features of the measured contamination distribution around the Shaft can be reproduced: the spatial extent and general activity levels of the dominant rock contaminant, Sr-90; the sparsity and low rock contamination levels of $\mathrm{Cs}, \mathrm{U}$, and $\mathrm{Pu}$; and the desorption of $\mathrm{Sr}$ from ion exchange sites due to competition from major cations from seasonally-variable marine aerosols and road salt application.

Model variants considered showed that: a thinner zone of alteration around discontinuities (decreased from 10 to $5 \mathrm{~mm}$ ) increased the mobility of $\mathrm{Sr}$ due to reductions in the volume of rock for matrix diffusion and the amounts of sorbing minerals, whereas the mobility of $U$ and $\mathrm{Pu}$ were unchanged (due to an excess of mineral sorption sites); time-dependent variations in water 
chemistry (fresh alternated with brackish water on an annual basis) served to increase the mobility of Sr relative to fresh water alone (an approximate $50 \%$ increase in spatial extent over 50 years); and fewer sorbing minerals (by a factor of 10) increased the mobility of Sr and Cs, whereas the mobility of $\mathrm{U}$ and $\mathrm{Pu}$ were unchanged due to an excess of mineral sorption sites. A smaller discontinuity aperture (decreased from 250 to $170 \mu \mathrm{m}$ ) did not produce results dramatically different from the base case, but aqueous concentrations of Cs were increased (due to preferential sorption of $\mathrm{Cs}$ on the discontinuity surface itself, rather than in the alteration zone). A lower source-term concentration for $\mathrm{Pu}\left(2.0 \mathrm{E}-9\right.$, reduced from $\left.2.0 \mathrm{E}-7 \mathrm{~mol} \mathrm{l}^{-1}\right)$ produced lower, and more realistic activities of $\mathrm{Pu}$ sorbed in the geosphere.

The $K_{d}$ model of sorption produced a good fit to the field data, increasing confidence in the use of this assumption in larger-scale performance assessment modelling. The adoption of a mechanistic model, rather than a $K_{d}$-based approach highlights that: activities of contaminants at or near the Shaft wall could be much greater than a $K_{d}$ approach would suggest, and activities in more distal regions could be higher; contaminants sorbed by reversible ion exchange (e.g. Sr), show that time-dependent variations in water chemistry can affect distributions of contamination through competitive sorption effects; and uncertainties regarding the abundances of sorptionactive minerals can affect predicted patterns of contamination through consideration of 'saturation' of sorption sites in chemical models, which is not considered in the $K_{d}$ approach.

\section{ACKNOWLEDGMENTS}

Funding from Dounreay Site Restoration Limited is gratefully acknowledged.

\section{REFERENCES}

[1] N.L. Jefferies, T.R. Lineham, M.C. Manning et al., Nirex Report No. NSS/R305, 2001.

[2] J.P. McKinley, J.M. Zachara, S.C. Smith et al., Geochim. Cosmochim. Acta 71, 305 (2007).

[3] C.A.J. Appelo and D. Postma, Geochemistry, Groundwater and Pollution. (A.A. Balkema, Rotterdam, 1994).

[4] M.H. Bradbury and B. Baeyens, J. Contam. Hydrol. 42, 141 (2000).

[5] M. Zavarin and C.J. Bruton, LLNL Report No. UCRL-TR-208673, 2004. 